\title{
O USO DE AULAS EXPERIMENTAIS NO ENSINO DE SOLUÇÕES
}

\author{
Apresentação: Comunicação Oral \\ Welly Evilly da Silva Vieira ${ }^{1}$; Higor Diego Farias de Melo²; Anelyssa Drielly Josefa da Silva ${ }^{3}$ \\ Cláudio Henrique Alves Perdigão ${ }^{4}$; Kilma da Silva Lima Viana ${ }^{5}$.
}

\section{Resumo}

Há evidências que apontam que, a relação entre teoria e prática nas aulas de Química se faz necessária, visto que, esta é uma ferramenta eficaz que pode ser utilizada para despertar o interesse nos discentes pela disciplina e auxiliar no processo de aprendizagem, porquanto, um conteúdo é mais bem fixado quando este mantém uma conexão com algum fenômeno que o estudante apresenta certa familiaridade ou possa observá-lo de forma presencial. A experimentação no que diz respeito ao ensino de Química constitui-se de uma ferramenta auxiliar, de grande eficácia na construção de conceitos. O presente trabalho teve como objetivo aplicar nova metodologia de ensinoaprendizagem para a turma de $2^{\circ}$ ano do Ensino Médio de uma escola Pública: ETE - Prof. José Luiz de Mendonça, com 61 alunos, localizada no município de Gravatá - PE. Ao final da pesquisa, foi possível concluir que, as aulas experimentais facilitam o aprendizado e despertam o interesse da maioria dos alunos, o que as tornam uma ferramenta didática que pode ser constantemente usada pelos professores de Química. Logo, é importante destacar que todos os resultados que encontramos em meio ao diálogo com os discentes, permitem argumentar em favor de atividades experimentais, pois estas incentivam os estudantes a questionar, pesquisar, refletir e agir, nos parâmetros e contextos que essa ciência tão relevante, engloba. É importante frisar que os estudantes gostam desse tipo de abordagem e se sentem motivados quando a mesma é proposta, desse modo o desenvolvimento dessas aulas é uma importante ferramenta para o ensino de Química.

Palavras-Chave: Aprendizagem, Ensino de Química, Experimentação

\section{Introdução}

Química é a ciência que trata da matéria e de suas transformações, portanto pode-se considerar que ela está presente em todo o mundo material que nos rodeia. Foi por meio desta ciência que avanços nos setores industrial, farmacêutico, alimentício, bélico, entre outros, puderam ser obtidos e aprimorados durante o decorrer da história. (VANIN, 2005).

\footnotetext{
${ }^{1}$ Licenciatura em Química, IFPE, wellyevilly@hotmail.com

2 Licenciatura em Química, IFPE, higordiego@outlook.com

${ }^{3}$ Licenciatura em Química, IFPE, anelyssa_drielly125@hotmail.com

${ }^{4}$ Professor da Licenciatura em Química, IFPE, claudio.perdigao@vitoria.ifpe.edu.br

${ }^{5}$ Professora da Licenciatura em Química, IFPE, kilma.viana@vitoria.ifpe.edu.br
} 
Desse modo, a Química torna-se um corpo de conhecimentos que auxilia na compreensão do nosso cotidiano. É uma ciência, essencialmente, de natureza experimental, mas que vem sendo discutida e ministrada em vários centros educacionais e dos diversos níveis, dando-se ênfase aos aspectos teóricos em detrimento aos aspectos práticos, limitando-se nas práticas tradicionais, com ênfase na teoria e na memorização de fórmulas e resolução de problemas matemáticos. Essa dissociação da experimentação com o ensino da Química em sala de aula acarreta em problemas para a aprendizagem dos conceitos e, consequentemente, o desinteresse dos estudantes pela área (Perdigão e Lima, 2010). À vista disso, Ferreira et al (2010) destaca que a Química Experimental é um instrumento auxiliar da educação que contribui para formação de conceitos.

De acordo com Medeiros et al (2010) a metodologia empregada por professores não consegue fazer um paralelo entre as relações das teorias químicas com contextos científicos, sociais e tecnológicos. Logo, os estudantes enxergam essa disciplina com "ar de preconceito", pois a maneira como o docente ministra as aulas não abrange de forma satisfatória toda a importância e complexidade que é incumbida a esta área do conhecimento.

Como forma de romper com essa perspectiva negativa construída em torno da Química, um recurso a ser adotado é o uso de experimentos que possam além de comprovar a teoria vista, envolver os estudantes com fenômenos que ocorrem no dia a dia, possibilitando assim, um estudo contextualizado.

Segundo a visão de Silva (2007), para se formar estudantes-cidadãos capazes de pensar criticamente, de atuar em sociedade e possuir saberes científicos sistematizados é necessário fazer uma aproximação entre o conhecimento científico e a realidade do discente. Em outras palavras, um ensino prático e contextualizado torna-se importante, principalmente no que se refere à Química, posto que o estudante passa a compreender os conteúdos ministrados em sala de aula, correlacionando teoria e prática.

Diante disso, a pesquisa teve o objetivo de analisar as relações existentes entre o uso da experimentação nas aulas de Química, mais precisamente no conteúdo de "Soluções" e a melhoria de aprendizado.

\section{Fundamentação Teórica}

A Química se faz presente no mundo muito antes da história escrita, sendo constatada como uma de suas primeiras representações, a descoberta do fogo. A partir desse fenômeno foi possível desenvolver inúmeros avanços para a época. Assim como na antiguidade, a Química continua proporcionando muitos desenvolvimentos para a humanidade, como a confecção de produtos têxteis, tinturas, polímeros, metais e derivados. (VANIN 2005). 
Apesar de todas as suas contribuições, a Química ainda é vista sob uma visão negativa, principalmente no que se diz respeito a ela como componente curricular nas escolas, logo a metodologia empregada por professores não conseguem fazer um paralelo entre as relações das teorias desta disciplina com contextos científicos, sociais e tecnológicos.

É preciso ter em mente que, o fato do ensino de Química se referir as Ciências da natureza, pode-se explorar de forma dinâmica e contextualizada os conteúdos relacionadas à mesma no âmbito escolar, despertando assim, maior interesse nos discentes. Um dos recursos atrativos que podem ser utilizados são as atividades experimentais.

Conforme (FERREIRA et al, 2010), a experimentação no que diz respeito ao ensino de Química constitui-se de uma ferramenta auxiliar, de grande eficácia na construção de conceitos. Mas segundo Hodson (1988) para que esta eficácia seja garantida é necessário conduzir e planejar as experimentações de acordo com os objetivos propostos pela aula, tais como, demonstrar uma hipótese, coletar dados, demonstrar um determinado fenômeno, etc. Então, não basta somente estar disposto a realizar um experimento com um determinado grupo de alunos. É também necessário planejar esta prática de forma que a mesma contribuía, significativamente, para o aprendizado do estudante.

Analisando a experimentação sob a óptica de docentes temos que, são duas as principais finalidades desta prática. A primeira esta relacionada ao uso das experimentações para confirmar uma determinada teoria, visto que, em relação à disciplina de Química, existe uma intrínseca conexão entre a parte teórica e a parte prática, pois é através desta última que pode-se obter de forma concreta, a confirmação dos conceitos expostos. A segunda finalidade se direciona ao aprendizado por meio da prática. É por meio das atividades experimentais que o estudante tem a oportunidade de manusear informações de tal forma a possibilitar a construção de conceitos (MOURA e CHAVES, 2009).

Bueno et al (2009) também faz uma ressalva sobre o papel do professor, evidenciando que estes, por sua vez, precisam estar atentos a enorme distância que tende a se estabelecer entre o mundo da ciência e o cotidiano. Convenções, enunciados, conceitos, teorias, modelos e leis podem á primeira vista ser tão incompreensíveis quanto palavras e frases de uma língua estrangeira. O docente além de trabalhar a experimentação interligada com a teoria, precisa encontrar pontos de contato entre o conteúdo a ser ministrado e os conhecimentos atuais do estudante.

É notório que, por mais que seja necessária a atenção dos professores para com os discentes, em relação à metodologia, ainda existem escolas, e na maioria da rede estadual de ensino segundo pesquisas, onde os alunos apresentam um déficit de aprendizagem no que diz respeito à disciplina 
de Química. Isso acontece devido à ausência de infraestrutura para a realização de novas práticas educacionais, como por exemplo, a experimentação.

É importante criar estratégias para a inserção das práticas experimentais no ensino de Química, pois de acordo com Carneiro (2009), a experimentação pode proporcionar meios para a criação de problemas concretos, integrantes do cotidiano dos alunos e que possibilitem a contextualização da teoria abordada, além de, proporcionar aos discentes as condições necessárias para elaborar questionamentos de cunho investigativo e de valor significativo para a aprendizagem dos mesmos.

Indo de encontro a Souza (2011), temos mais uma vez a afirmação de que as aulas experimentais são de suma importância para o processo de aprendizado do estudante, pois, as mesmas, permitem aproximar de forma prática a teoria que é apresentada ao discente proporcionando-lhe a oportunidade de investigar, vivenciar e experiênciar uma contextualização das mesmas com assuntos cotidianos. Visto que, em termos de aprendizado, um conteúdo é melhor fixado quando este mantêm uma conexão com algum fenômeno que o discente apresenta certa familiaridade ou possa observá-lo de forma presencial.

\section{Metodologia}

Essa pesquisa apresenta uma natureza quanti - qualitativa, tendo como campo a ETE Prof. José Luiz de Mendonça, escola Estadual, localizada no município de Gravatá- PE. Os sujeitos foram 61 estudantes que cursam $2^{\circ}$ ano do Ensino Médio.

$\mathrm{O}$ experimento foi realizado primeiramente com $50 \%$ dos estudantes, posto que, o laboratório apesar de ter uma boa infraestrutura em relação aos materiais e reagentes, não comporta os $100 \%$ de alunos. Por conseguinte, os discentes foram divididos em 4 (quatro) grupos, sendo que, para cada grupo foi disponibilizado uma bancada com os materiais necessários para a realização do experimento "Preparo de Soluções".

De antemão, é importante destacar que a abordagem do experimento foi feita a partir das cinco etapas do Ciclo da Experiência Kellyana, (Kelly, 1963). Como a turma foi dividida em 2 (duas) para a realização do experimento, vale ressaltar que ambas as partes vivenciaram as etapas deste ciclo.

Na primeira etapa (Antecipação), foram levantados os conhecimentos prévios dos estudantes sobre o conteúdo de Soluções. Na segunda etapa (Investimento), foi apresentada uma aula dialogada por meio de slides e lousa sobre o assunto. Na terceira etapa (Encontro), realização do experimento, com levantamento de hipóteses, debates, interação. Posteriormente, ocorreu a quarta etapa (Confirmação ou Desconfirmação), onde os estudantes, por sua vez, confirmaram ou 
desconfirmaram se suas hipóteses iniciais condisseram com o resultado da experimentação e com a aula dialogada. Para o fechamento desse ciclo, foi realizada a quinta etapa (Revisão Construtiva), nessa, foi aplicado um questionário de 5 (cinco) questões que tratavam sobre a relação existente entre a experimentação e a aprendizagem do conceito (soluções) em Química.

Em seguida, depois da separação das equipes, foi exposta no quadro uma tabela que contemplava todos os grupos. Para cada equipe foi disponibilizado valores de volumes, e concentrações em quantidade de matéria distintas. De posse desses dados, os estudantes deveriam calcular a massa necessária do soluto em questão (nesse caso, foi disponibilizado diferentes sais para os grupos: sulfato de magnésio, sulfato de cobre, cloreto de sódio e sulfato de níquel) que deveria ser pesado na balança para o preparo da solução.

Depois da pesagem, 1 (um) líder do grupo adicionou a quantidade pesada em um béquer e em seguida foi adicionado a quantidade de água exposta na tabela para aquela respectiva equipe. Por consequência os respectivos líderes foram instruídos a agitar a solução, a fím de dissolver o soluto. Ao término da prática experimental, os estudantes foram induzidos a refletirem sobre o experimento, debatendo sobre as expressões de concentrações e respectivas fórmulas, assim como as características do assunto abordado "Soluções". Após finalizar com esta parcela de estudantes, os outros $50 \%$ restantes vivenciaram a mesma prática experimental.

\begin{tabular}{|l|l|l|l|}
\hline & VOLUME & MOLARIDADE & MASSA \\
\hline GRUPO 1 & $100 \mathrm{~mL}$ & $50 \mathrm{~mol}$ & $?$ \\
\hline GRUPO 2 & $150 \mathrm{~mL}$ & $40 \mathrm{~mol}$ & $?$ \\
\hline GRUPO 3 & $100 \mathrm{~mL}$ & $30 \mathrm{~mol}$ & $?$ \\
\hline GRUPO 4 & $150 \mathrm{~mL}$ & $10 \mathrm{~mol}$ & $?$ \\
\hline
\end{tabular}

Tabela 1: Exemplo da tabela exposta no quadro. Fonte: Própria

A seguir, expomos as perguntas do questionário aplicado, para fins de informação ao leitor:

\section{Questionário Aplicado;}

1) Em relação aos conceitos de Química, você aprende melhor:

( ) somente com aulas teóricas.

( ) somente com os experimentos.

( ) com a junção de teoria e experimentação.

2) O experimento te ajudou de alguma forma em relação ao conteúdo de soluções?

$$
\text { ( ) Sim ( ) Não }
$$


3) Para uma mistura ser considerada uma solução ela precisa ter quantas fases?

$$
\text { ( ) } 3 \text { fases ( ) } 2 \text { fases ( ) } 1 \text { fase }
$$

4) Imagine que foi colocada em um copo certa quantidade de água. Logo em seguida foi-se adicionando sal de cozinha até a mistura apresentar acúmulo de sal no fundo do copo. $\mathrm{Na}$ situação dita, qual foi o tipo de solução formada?
( ) Saturada
( ) Insaturada
( ) Supersaturada

5) Quantos gramas de cloreto de sódio (sal de cozinha) precisam ser adicionados para fazer uma solução de concentração 5.0 molar (molaridade) em um recipiente contendo 10 litros de água?

Com relação às atividades experimentais, expõe-se a seguir os materiais e reagentes utilizados:

\section{$\underline{\text { Materiais e reagentes utilizados nos experimentos: }}$}

\section{Experimento: Preparo de Soluções;}

\section{Materiais e Reagentes (para cada grupo);}

- 1 funil de vidro;

- 1 balão volumétrico;

- 1 béquer

- Papel de filtro;

- Balança;

- Espátula;

- Pisseta;

- Bastão de vidro;

- Água;

- 4 (quatro) sais distintos: sulfato de magnésio, sulfato de cobre, cloreto de sódio e sulfato de níquel (1 para cada grupo).

\section{Resultados e Discussão}

O experimento proposto para iniciar as atividades teve o objetivo de expor os estudantes à prática experimental. É importante ressaltar que os resultados foram satisfatórios, os alunos participaram bastante da atividade prática. 
Quanto aos resultados quantitativos, foram observados os dados referentes às respostas dadas pelos 61 alunos participantes da atividade.

Em relação à primeira pergunta que questionou o melhor aprendizado dos conceitos químicos com aulas teóricas, somente com os experimentos, ou com a junção da teoria e experimentação, temos o resultado no gráfico a seguir:

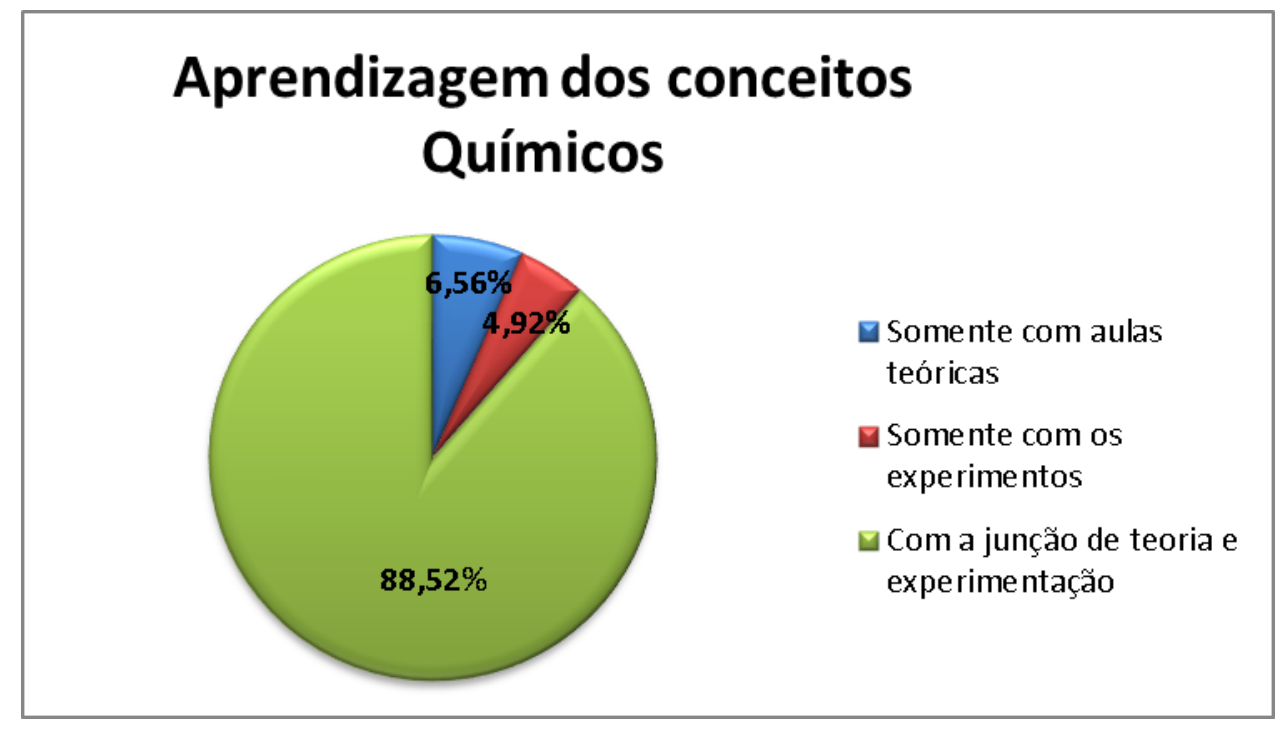

Gráfico 1: Aprendizagem dos conceitos Químicos. Fonte: Própria.

Observa-se que dentre os 61 (sessenta e um) alunos, 4 (quatro) afirmaram que aprendiam apenas com as aulas teóricas (o que equivale a 6,56\%); 3 (três) alunos disseram que aprendiam somente com os experimentos (correspondente a 4,92\%); enquanto que 54 (cinquenta e quatro) estudantes, (o que equivale a 88,52\%) admitiram aprender com a junção da teoria e da experimentação. Isto comprova o fato da experimentação unida à teoria auxiliar no processo de ensino-aprendizagem, pois segundo Freire (1997), para compreender a teoria é preciso experienciála.

Evidenciando a segunda questão, que perguntava exatamente se o experimento havia ajudado de alguma forma a entender o conteúdo de Soluções, dos 61 (sessenta e um) alunos, 58 (cinquenta e oito) afirmaram que sim (o equivalente a 95,08\%); enquanto 3 (três) alunos responderam não (correspondentes a 4,92\%). Isso infere dizer que, a realização de experimentos, em Ciências, particularmente em Química, representa uma excelente ferramenta para que o estudante compreenda o conteúdo e estabeleça a indissociável relação entre teoria e prática. Bazin (1987), afirma que a experiência no ensino de Ciências é de maior significância ao comparar ao ensino marcado apenas pela memorização da informação, método tradicionalmente empregado nas salas de aula. 
A terceira, quarta e quinta questão, procuram analisar se o estudante aprendeu de fato o conteúdo de Soluções. Em relação à terceira questão, a qual perguntava as características das soluções com relação às fases, obteve-se o seguinte resultado:

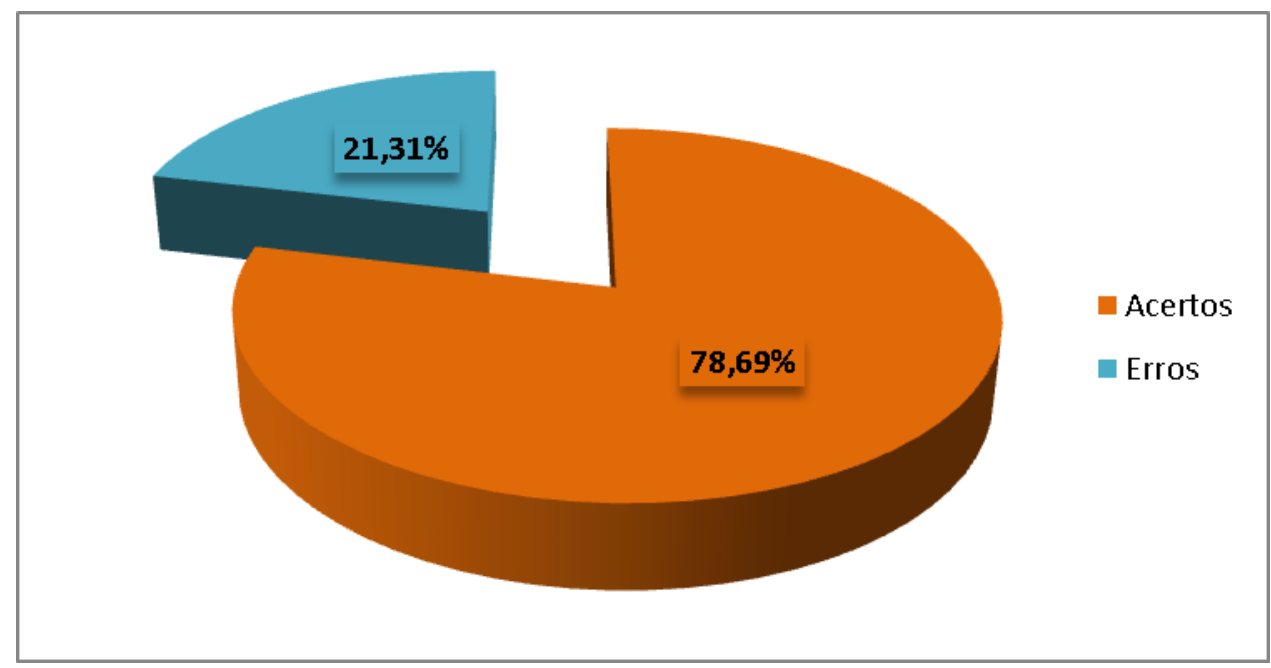

Gráfico 2: Quantitativo dos alunos que acertaram e os que erraram a terceira questão. Fonte: Própria.

Percebe-se que mais da metade dos alunos, 48 (quarenta e oito), correspondente a 78,69\% acertaram a terceira questão. Com relação ao quarto quesito: "Imagine que foi colocada em um copo certa quantidade de água. Logo em seguida foi-se adicionando sal de cozinha até a mistura apresentar acúmulo de sal no fundo do copo. Na situação dita, qual foi o tipo de solução formada? Saturada, insaturada ou supersatura? 57 (cinquenta e sete) estudantes acertaram (o que corresponde a 93, 44\%); enquanto, apenas 4 (quatro), erraram (equivalente a 6,56\%). Desse modo, é perceptível que os estudantes conseguiram fazer uma relação entre experimento, teoria e cotidiano, por isso a quantidade de discentes que acertaram a quarta questão foi superior em relação ao terceiro quesito, o qual tem um enfoque mais teórico.

A última pergunta evidenciava os cálculos referentes ao conteúdo de Soluções, onde se teve o resultado exposto no gráfico a seguir:

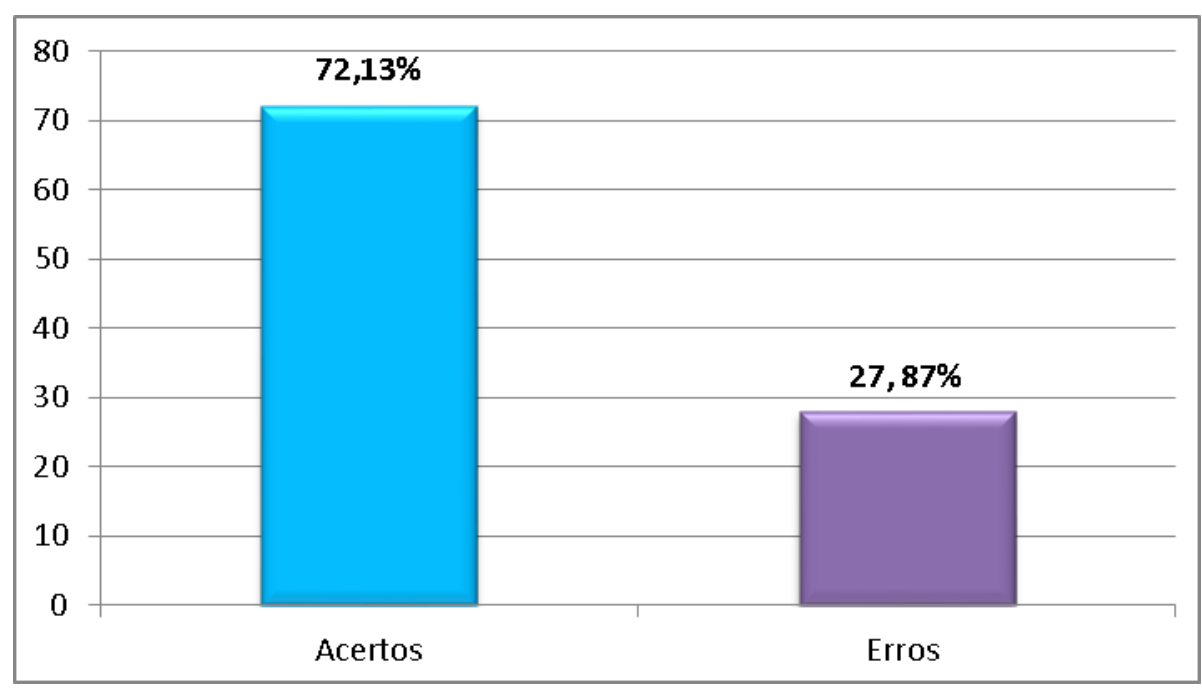


Gráfico 3: Quantitativo de alunos que acertaram, e que erraram a quinta questão. Fonte: Própria.

É importante evidenciar que quando se trata de questões que contemplam fórmulas e cálculos, muitos alunos não conseguem responder de forma correta, visto que é preciso ter em mente a fórmula adequada para a resolução e isso remete a um sistema de memorização, onde os estudantes procuram decorar apenas para a realização de provas e na maioria das vezes não conseguem responder porque esquecem, comprovando desse modo que decorar não é aprender. Em relação às respostas referentes à quinta questão, percebe-se que houve erros, entretanto mais da metade da turma conseguiu responder de forma correta. Logo, os docentes devem investir em metodologias que visem à contextualização, às práticas experimentais, correlacionando-as com a teoria evidenciada em sala de aula, tornando assim, mais potencialmente significativo o processo de ensino-aprendizagem.

As figuras a seguir mostram a realização da atividade experimental supracitada:

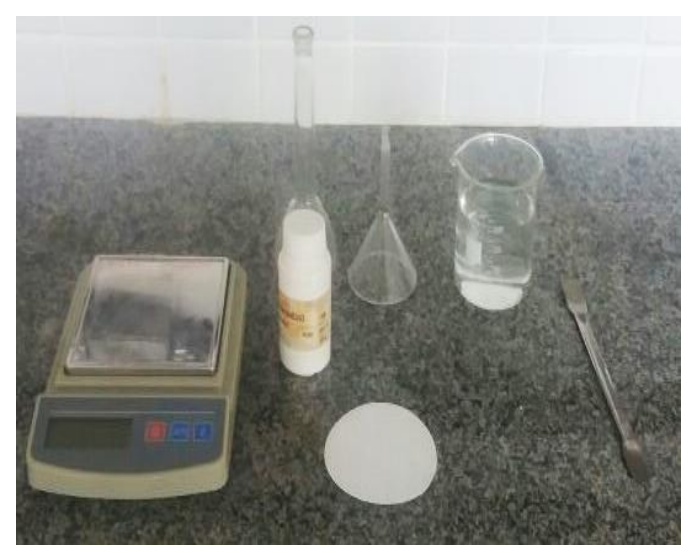

Figura 1. Materiais utilizados no experimento.

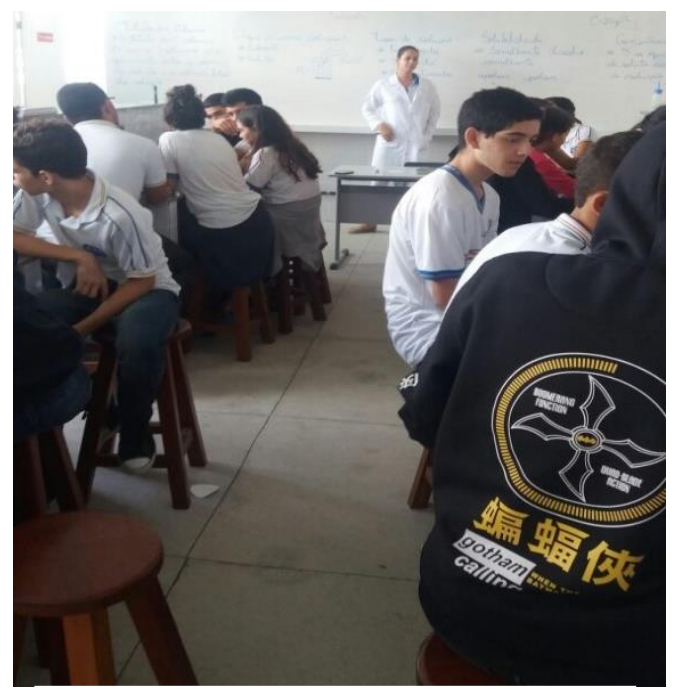

Figura 2. Aula dialogada 


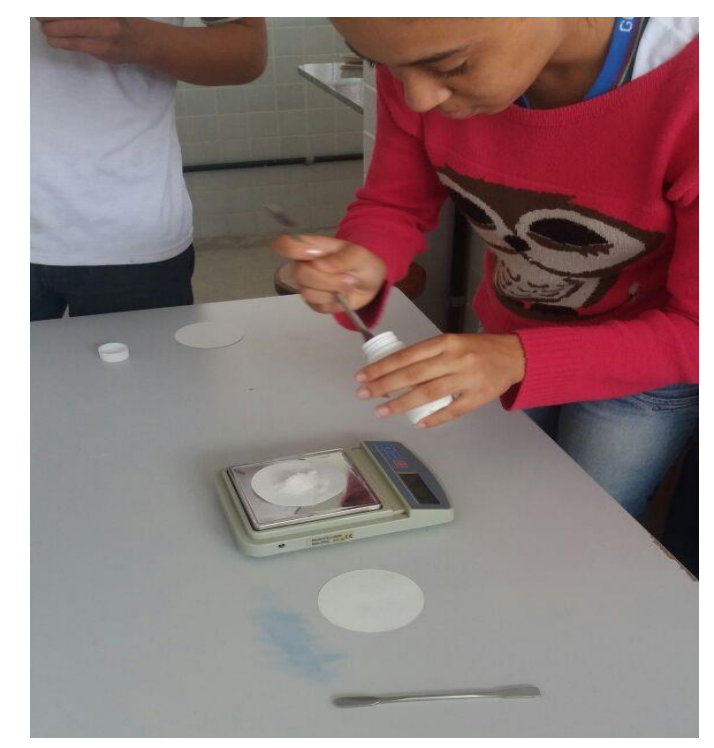

Figura 3. Pesagem do soluto para o preparo da solução.

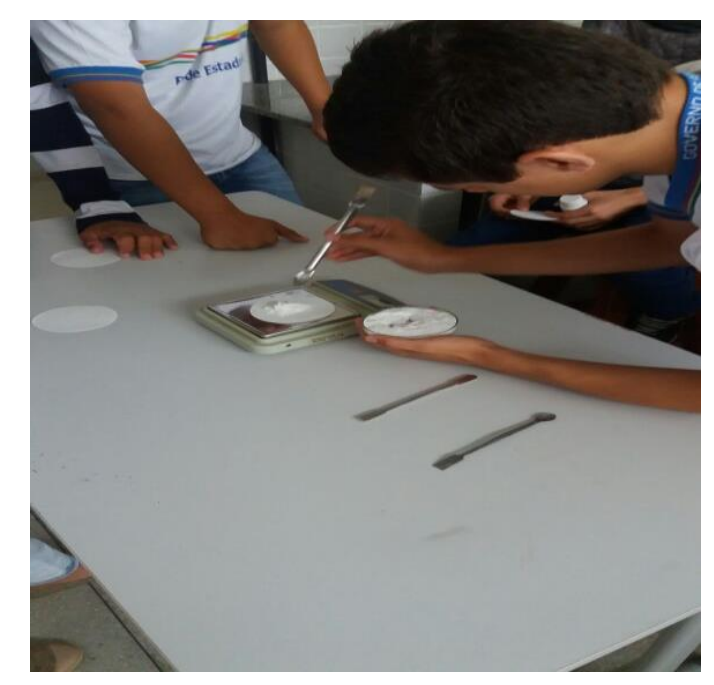

Figura 4. Pesagem do soluto para o preparo da solução.

\section{Conclusões}

Diante do exposto, conclui-se que a utilização de aulas experimentais é importante para a construção do conhecimento científico, sendo assim é extremamente relevante para ensino de Ciências. Em relação à disciplina de Química, os docentes devem utilizar novas metodologias, como por exemplo: aulas práticas e amostragem, visando atrair o aluno a participar do processo de aprendizagem, visto que a experimentação promove investigação e levantamento de hipóteses. É preciso destacar que apesar da importância que é incumbida à experimentação, é fundamental que a teoria esteja relacionada à mesma, pois teoria e prática são uma via de mão-dupla, para contextualizar, investigar, questionar, retomar conhecimentos e também reconstruir conceitos. 


\section{Referências}

- BAZIN, M. Three years of living science in Rio de Janeiro: learning from experience. Scientific Literacy Papers, 67-74. (1987). Secretaria de Educação Fundamental. Parâmetros Curriculares Nacionais: Ciências Naturais/ Secretaria de Educação Fundamental. Brasília: MEC/SEF;

- BUENO, L., MOREIRA, K. C., SOARES, M., DANTAS, D. J., SOUSA, A. C., WIEZZEL, J., TEIXEIRA, M. F. S. O ensino de química por meio de atividades experimentais: a realidade do ensino nas escolas. Universidade Estadual Paulista "Júlio de Mesquita Filho" Faculdade de Ciências e Tecnologia/PRESIDENTE PRUDENTE; Junho/2009.

- CARNEIRO, C. G. Experimentação no ensino de Química: caminho e descaminhos rumo à aprendizagem significativa. Química Nova na Escola. Vol. 31, º3, Agosto 2009.

- FERREIRA, L. H. HARTWig, D. R. e OliVEIRA, R. C. Ensino experimental de Química: uma abordagem investigativa contextualizada. Química Nova, vol 32,2010;

- FREIRE, P. Pedagogia da Autonomia. Rio de Janeiro, 1997;

- HODSON, D. Experiments in Sciemce and Science Teaching Educational: Philosophy and Theory 20 (2), p. 53-66, 1988;

- KELLY, G. A. A theory of personality: the psychology of personal constructs. New York: W.W. Norton, 1963;

- MEDEIROS, E. L. OLIVEIRA, A. C. e PINHEIRO, A. N. O estudo de casos na formação de professores de Química. Química Nova, Fortaleza-Ce, Departamento de Química Analítica e Físico-química, UFCE Campus do Pici, vol 33, No. 9,1996-2002, 2010;

- MOURA, G. N.; CHAVES, S. N. Visões e virtudes pedagógicas do ensino experimental da Química. VII Encontro Nacional de Pesquisa em Educação de Ciência. Florianópolis, 8 de Novembro de 2009.

- PERdigÃO, C. H. A, LIMA, K, S. A prática docente experimental de Química no Ensino Médio. Anais do IV Educon. Aracaju - SE. Setembro de 2010;

- SILVA, E. L. Contextualização no ensino de Química: ideias e proposições de um grupo de professores. Dissertação (Mestrado)-Universidade de São Paulo. Instituto de Química. Depto. Química Fundamental. São Paulo 2007;

- SOUZA, J. R. T. Instrumentação para o ensino de química. Ed. UFPA, Belém-PA, 2011; 
- VANIN, J. A. Alquimistas e químicos o passado, o presente e o futuro. São Paulo: Moderna, 2005. 119p. 